\title{
El rol de las representaciones corporales mediáticas en la esfera sexual de personas de ideología feminista
}

\author{
Maialen Suarez-Errekalde \\ Raquel Royo Prieto \\ Universidad de Deusto. Facultad de Ciencias Sociales y Humanas. Equipo Deusto Valores Sociales \\ msuarez@deusto.es; raquel.royo@deusto.es
}

\section{Resumen}

Este artículo se enmarca dentro de una tesis doctoral que trata de analizar desde una perspectiva feminista las continuidades y rupturas del orden sexual heteropatriarcal analizando las relaciones de poder en las relaciones sexuales de activistas feministas y LGTBIQ+, así como de hombres a favor de la igualdad en Hego Euskal Herria. Mediante este artículo se pretende abordar uno de los principales ejes temáticos de la investigación: el nivel de adherencia a los roles de género tradicionales en las relaciones sexuales de personas feministas. Concretamente, queremos averiguar si las representaciones corporales estereotipadas y sexistas que los medios y las industrias culturales muestran afectan o no al modo en el que se desenvuelven sexualmente las personas pertenecientes a este colectivo, si existen diferencias al respecto en base al género y a la opción sexual, y, por último, si la ideología feminista que comparten influye de alguna manera en su asimilación o rechazo de los contenidos mediáticos mayoritarios. Para ello se han analizado 29 entrevistas en profundidad. Nos encontramos con que, efectivamente, estas representaciones influyen de manera bastante importante, sobre todo en personas cisexuales y/o heterosexuales, en los siguientes aspectos: la construcción del deseo y los modelos de atractivo, por un lado, y la autopercepción del propio cuerpo y las exigencias de los mandatos de género, por otro. Sin embargo, el feminismo les permite tomar conciencia y ser personas críticas al respecto.

Palabras clave: medios de comunicación; roles de género; sexualidad; heteronormatividad; patriarcado 
Abstract. The role of media body representations in the sexual sphere among people of feminist ideology

This article is framed within a doctoral thesis that examines the continuities and ruptures of the heteropatriarchal sexual order from a feminist perspective, with a focus on the power relations that emerge in the sexual relations of feminist activists, LGTBIQ+ activists, and men in favor of equality in the southern Basque Country. The article aims to address one of the main thematic areas of the research: the level of adherence to traditional gender roles in the sexual relations of feminist people. Specifically, we want to determine whether or not the stereotyped and sexist body representations in cultural media and industries affect these people's sexuality, if there are differences based on gender and sexual choice and, finally, if the feminist ideology they share influences their assimilation or rejection of mainstream media content in some way. For this purpose, 29 in-depth interviews have been analyzed. We find that these representations have a significant influence, especially among cisexual and/or heterosexual people, in two regards: the construction of desire and models of attractiveness on the one hand, and the self-perception of one's own body and gender mandates on the other hand. However, feminism allows them to be aware and critical about such issues.

Keywords: media; gender roles; sexuality; heteronormativity; patriarchy

\section{Sumario}

1. Introducción 5 . El rol de las industrias culturales

2. La sexualidad como constructo sociocultural de dominación (hetero) patriarcal: corrientes del siglo $\mathrm{xx}$ en la sexualidad de personas de ideología feminista

6. La subversión LGTBIQ+

3. El papel de las industrias mediáticas y culturales en la construcción de la sexualidad 4. Metodología

7. La toma de conciencia feminista

8. Conclusiones

Referencias bibliográficas

\section{Introducción}

Las preocupaciones feministas en torno a la sexualidad provienen del hecho de que la sexualidad femenina ha sido históricamente negada y vilipendiada en favor de una sexualidad androcéntrica y patriarcal basada en una doble moral sexual mucho más laxa y permisiva con los hombres (Greer, 1970; Millett, 1970; Koedt, 1972; Firestone, 1973; Daly, 1978; Dworkin, 1981). Con la irrupción de las tesis postmodernas y la teoría queer (Foucault, 1976; Butler, 1990, 1993), estas preocupaciones se extienden hasta abarcar las múltiples opresiones que sufren no solo las mujeres, sino también todas aquellas corporalidades que no encajan en las convenciones cisheteronormativas respecto al género y a la orientación sexual. Estos debates revelan cómo la sexualidad cumple un papel fundamental en la organización social y cómo, a través de la imposición de un modelo único de sexualidad social y moralmente viable, se generan múltiples relaciones de poder que se filtran en el ámbito sexual. Los medios de comu- 
nicación y las industrias culturales, en tanto que son uno de los principales agentes socializadores, constituyen unas piezas fundamentales en la construcción social de la sexualidad heteropatriarcal hegemónica, a través de la transmisión de contenidos y de mensajes que, por un lado, erotizan la desigualdad genérica y, por otro lado, invisibilizan las realidades que no acatan la normatividad sexual (Kim y Ward, 2004; Ward, 2002, 2003; Giles, 2006; García Muñoz y Martínez García, 2008). Ante estas cuestiones, la subjetividad feminista se revela como un requisito clave en aras de dar cuenta de estas relaciones de poder que surgen en el ámbito sexual, así como en relación con el surgimiento de la voluntad de cambio y subversión de las mismas (Ahmed, 2017).

Partiendo de estas bases teóricas, y con la firme creencia de que la sexualidad constituye un constructo social y político de carácter heteropatriarcal, este artículo se propone analizar el rol de las representaciones corporales mediáticas heterosexistas en el ámbito sexual de personas de ideología feminista. Pero, además, queremos comparar la realidad de distintos colectivos sexogenéricos en aras de averiguar si existen diferencias al respecto en base al género o a la orientación sexual, así como estudiar el impacto que genera la ideología feminista que comparten las personas participantes en relación con esta incidencia de las industrias culturales. El interés del presente artículo radica precisamente en dichas cuestiones. Para comenzar, la sexualidad es una temática relativamente escasa en la investigación social de nuestro contexto más inmediato, a pesar de que constituye un ámbito de gran represión heteropatriarcal; además, la mayor parte de los estudios que abordan estas cuestiones se centran en la opción heterosexual o, en los casos en los que se abarca otro tipo de sexualidades, se realiza de manera aislada, sin aunar en un único estudio las posibilidades existentes desde el aspecto identitario, lo cual ofrece una visión más parcial y sesgada de la realidad sociosexual. $Y$, por último, apenas se han encontrado investigaciones que se ocupen del posible factor diferenciador que puede constituir la ideología feminista. Para dar respuesta a todas estas cuestiones, se ha optado por un enfoque cualitativo que se ha resuelto a través de 29 entrevistas en profundidad.

El artículo comienza con la exposición de los principales debates teóricos relativos a la sexualidad entendida como un constructo discursivo de dominación heteropatriarcal, así como del estado de la cuestión en relación con las industrias culturales y su impacto respecto al orden sexual patriarcal y cisheteronormativo. Posteriormente, tras un breve apartado metodológico, se dedica una sección analítica a cada objetivo establecido, para finalizar con un apartado de conclusiones que se encarga de resaltar los principales hallazgos obtenidos.

\section{La sexualidad como constructo sociocultural de dominación (hetero) patriarcal: corrientes del siglo $\mathrm{xx}$}

Hace ya tiempo que las ciencias sociales vienen contestando la idea que durante siglos dominó tanto el panorama sexológico, así como el médico, el psicológico y el psiquiátrico occidental, de que la sexualidad es un aspecto totalmente natural e inherente al ser humano, una respuesta a unas pulsiones biológicas 
esenciales e inmutables. Al contrario, la creencia predominante en el ámbito académico crítico actual ha dejado atrás las tesis positivistas y aboga por teorías de corte construccionista que afirman que nuestra manera de entender, expresar, vivir y sentir la sexualidad está condicionada por factores históricos y socioculturales.

La preocupación por la sexualidad ha sido una constante en la lucha feminista, la cual ha desempeñado un papel determinante en esta consideración social de la sexualidad. La idea principal que el feminismo viene a constatar es que la sexualidad constituye un constructo de carácter patriarcal basado en el género como promotor de desigualdad. A finales de la década de 1960 y a principios de la de 1970, bajo el lema "lo personal es político», el feminismo radical dotó al sexo de un cariz profundamente político, dejando de manifiesto que es precisamente en el ámbito privado e íntimo de las personas donde se materializan las relaciones de poder que luego se reproducen en el resto de las esferas de la sociedad (Greer, 1970; Millett, 1970; Koedt, 1972; Firestone, 1973; Daly, 1978; Dworkin, 1981). En esta línea, MacKinnon (1989), por ejemplo, afirmó que toda experiencia femenina es en última instancia una experiencia masculina, puesto que los intereses y el poder de la sexualidad masculina son los que crean el significado universal de la sexualidad. Lo que básicamente viene a decir es que todo lo que construye a la mujer como un ser inferior es exactamente igual a todo lo que define a la sexualidad femenina y que, por ende, la desigualdad de género está constituida por un alto contenido erótico.

Si el punto en común entre todas estas autoras se centra en la consideración patriarcal de la sexualidad (entendiendo el patriarcado como un sistema de dominación masculina), Foucault (1976) lleva el debate más allá manifestando también que la sexualidad es una realidad política y sociohistórica, pero que está destinada a producir cuerpos normativos en términos de género y de orientación sexual.

En definitiva, el filósofo francés ofreció una teoría sobre la construcción social del sexo y de los cuerpos como efectos del poder disciplinario que, gracias a una gran tecnología biopolítica ${ }^{1}$ desplegada, consigue el objetivo opuesto a reprimir la sexualidad, produciendo por el contrario la consolidación de determinados cuerpos, sujetos y placeres coherentes o subversivos respecto al orden (hetero)sexual (Foucault, 1976: 48-64). En este sentido, la lectura cruzada de Wittig $^{2}$ y Foucault que propone Preciado (2005: 113-116), destacada autora

1. La biopolítica es para Foucault «la organización del poder sobre la vida» (1976: 169). Se basa en una tecnología de poder que se aplica sobre el conjunto de la población y que se traduce en un nuevo saber, en una nueva regulación y en un nuevo control científico destinado a administrar los cuerpos y la vida de dicha masa de población. Se trata de un mecanismo que convierte al poder-saber en un agente de control y transformación de la vida humana (Foucault, 1976: 168-173).

2. Monique Wittig (1992a) fue una de las primeras autoras en definir la heterosexualidad como un régimen político totalizador que genera la diferencia sexual, así como la subsecuente subordinación de las mujeres. Preciado (2005: 115) establece la unión de este sistema opresor con la noción de biopolítica de Foucault, porque Wittig (1992b) define las funciones de reproducción como una especie de control o regulación planificada de la vida. 
por sus aportes a la teoría queer, viene a demostrar que la (hetero)sexualidad constituye otra tecnología biopolítica dedicada a producir cuerpos heteronormativos. Es precisamente aquí donde Foucault y la teoría queer de finales del siglo Xx intersectan. A grandes rasgos, la teoría queer, con autoras como Judith Butler (1990), contribuye a deconstruir las categorías socioculturales de sexo y de género, manifestando que dichas categorías, así como la coherencia entre sexo, género y sexualidad, son también sendas construcciones socioculturales. Siguiendo a Foucault, Butler $(1990,1993)$ afirma que la inteligibilidad cultural de los cuerpos ${ }^{3}$ se regula precisamente a través de la falsa coherencia que se espera mantener entre sexo, género y deseo, cuya repetición normativa es lo que produce en última instancia la diferencia sexual binaria. Dicho de otro modo, las categorías o identidades de género se generan dentro de la norma heterosexual, con lo cual la sexualidad es, además de una construcción patriarcal, un dispositivo activo cuya función es salvaguardar el orden dicotómico y hetero hegemónico a través de la producción de cuerpos y sujetos normativos. Así, los cuerpos que escapan a la lógica de la norma en parámetros de sexualidad y de género, pero también de capacidad, de origen, de etnia, etc., pasan a formar parte de lo abyecto, de lo ininteligible o de lo monstruoso, aquello que de hecho conforma la otredad necesaria para la existencia de la normatividad, pero que al mismo tiempo es socialmente rechazado y sancionado (Platero y Rosón, 2012). En este sentido, mientras para el feminismo radical el sujeto oprimido es la mujer, la teoría queer, fiel a sus raíces postmodernas y a su énfasis en la diferencia, desvía su atención hacia todos aquellos cuerpos y sujetos no inteligibles según los parámetros normativos de la sociedad.

Por otro lado, el feminismo radical equipara el poder con la dominación masculina sobre las mujeres, y se considera que esta es ubicua y generalizada. Desde esta lectura que subraya la opresión femenina, el empoderamiento o la capacidad de subversión de las mujeres, en definitiva, su agencia sexual, resultaría prácticamente imposible epistemológicamente hablando. Ante esto, la relectura foucaultiana sobre el poder en términos productivos e ineludibles sirve para dar cuenta de las transformaciones que efectivamente están emergiendo en el ámbito de la sexualidad en tanto que resistencias al sistema heteropatriarcal. El autor francés, al contrario que la teoría feminista de su época, afirma que el poder no es un dispositivo que un único ente detenta generando posiciones de dominación y subordinación, sino que se ejerce en una enmarañada red de relaciones múltiples que atraviesa el cuerpo social, constituyéndose como una instancia ineludible de la cual nadie puede escapar (Foucault, 1979). Esto le lleva a afirmar que «no existen relaciones de poder sin resistencias» (Foucault, 1979: 171), puesto que aceptar estas ideas conlleva que la capacidad de ejercer poder reside en cualquiera, lo que posibilita nuevas redistribuciones y configuraciones que hacen de la sexualidad un ámbito en constante cambio

3. La inteligibilidad cultural de los cuerpos se refiere al conjunto de mensajes simbólicos y socioculturales que encarnan los cuerpos a efectos de constituirse como sujetos comprensibles a ojos del resto en base a los parámetros normativos de la sociedad (Butler, 1990, 1993). 
y construcción (Hicks y Jeiyasingham, 2016: 2359). Esta es precisamente otra herencia foucaultiana que reviste la teoría queer, la cual comparte la creencia en la imposibilidad de un espacio exterior al poder, pero que, sin embargo, fomenta la subversión a través de la resistencia a la normatividad hegemónica, al considerar que el régimen heterosexual es una entidad que, en tanto que constructo social, es precaria e inestable; es decir, a pesar de no poder significar fuera de la diferencia sexual hetero binaria, una proliferación de géneros y sexualidades puede desestabilizar la matriz heterosexual dejando al descubierto su falacia (Butler, 1990). Estas consideraciones posibilitan la subversión o la transgresión de los códigos culturales patriarcales y heteronormativos mencionados, superando la imposibilidad epistemológica del feminismo radical respecto al poder femenino, y dan cuenta a su vez de los posibles cambios que se puedan producir en los esquemas (hetero)sexuales tradicionales y sus respectivos niveles de actuación.

\section{El papel de las industrias mediáticas y culturales en la construcción de la sexualidad}

Ante esto, los medios de comunicación y las industrias culturales en general constituyen mecanismos indispensables en la socialización sexual; a través de ellos observamos e interiorizamos el significado de lo erótico, de lo sexual, de lo atractivo, así como cuáles son los comportamientos sexuales «adecuados y sanos» y cuáles, en cambio, son los «desviados» (Kim y Ward, 2004; Ward, 2002, 2003; Giles, 2006; García Muñoz y Martínez García, 2008). Además, existe un amplio consenso en que dicha socialización se realiza en base a los términos arriba descritos, hacia una sexualidad patriarcal y hacia una sexualidad heteronormativa. Por ejemplo, hallamos estudios que muestran que tanto hombres como mujeres se representan de una manera completamente estereotipada y sexista (Furnham y Bitar, 1993; Díaz et al., 2010; Carretero García, 2014), lo que fomenta la doble moral sexual (Abramson y Mechanic, 1983; Dempsey y Reichert, 2000; Ward, 2003; Ménard y Kleinplatz, 2008; Furnham y Paltzer, 2010) y, básicamente, es congruente con los esquemas heterosexuales tradicionales (Ménard y Cabrera, 2011; Gamble, 2016). Más concretamente, algunos estudios establecen las correlaciones entre la exposición a contenidos mediáticos heterosexistas y posteriores actitudes perjudiciales y totalmente dañinas para la igualdad de género, incluso para la salud y la integridad de las personas, como, por ejemplo, los efectos en la autopercepción del cuerpo y los comportamientos insalubres derivados de ello (Cahill y Mussap, 2007; Noriega, 2012), el hecho de considerar a las mujeres meros objetos sexuales (Peter y Valkenburg, 2007; Yao et al., 2010) o incluso fomentar el acoso sexual por parte de los hombres hacia las mujeres (Yao et al., 2010). En este contexto, parece que la pornografía incide especialmente en la educación sexual de las personas (Arrington-Sanders et al., 2015), ya que, además, tal y como apuntan Braithwaite et al. (2015) y Morales (2016), el aumento del acceso a internet ha hecho que la pornografía sea más asequible que nunca, y es más, desde 
todo tipo de dispositivos y a cualquier edad, intencionadamente o no. En la misma sintonía que los estudios recientemente mencionados existe un creciente cuerpo teórico que sugiere que el uso corriente de la pornografía fomenta actitudes y valores heteropatriarcales e incluso violentas. Estas ideas no son nuevas, puesto que las ya mencionadas Dworkin y MacKinnon, comenzaron a lanzar campañas antipornografía (Dworkin, 1981; Dworkin y MacKinnon, 1988; MacKinnon, 1991), manifestando que la pornografía era central a la opresión de la mujer y al sistema sexual masculino, así como la plaga que conducía a la violencia machista con sus mecanismos de humillación, cosificación, violencia, denigración y difamación. No lejos de esas aseveraciones, entre la investigación especializada en la temática, encontramos estudios que avalan que la pornografía tradicional desempeña un papel transmisor de la ideología heteropatriarcal dominante (Morales, 2016), que fomenta comportamientos sexuales considerados de riesgo (Arrington-Sanders et al., 2015; Braithwaite et al., 2015), que promueve la dominación masculina y la sumisión femenina en las prácticas sexuales (Wright, Sun et al., 2015; Wright, Tokunaga et al., 2015), que refuerza actitudes como la cosificación sexual de las mujeres (Bridges et al., 2003), que aumenta la agresión hacia estas (Hald et al., 2010; Wright, Sun et al., 2015) y que incluso provoca una mayor aceptación de la violación (Foubert et al., 2011). Por su parte, el estudio de Fithern (1996) muestra que incluso la llamada pornografía gay ha hecho uso de los componentes de la heterosexualidad hegemónica en su industria, donde las dinámicas de poder inundan la pantalla glorificando la masculinidad y la virilidad tradicional.

Todo esto se configura en torno a unos modelos de atractivo marcados por unos cánones de belleza muy concretos, donde imperan la hipersexualización y la cosificación femeninas (Carretero, 2014; Díaz et al., 2010; Cobo, 2015), en una representación de la realidad extremadamente parcial e irreal, mientras que la diversidad de otro tipo de cuerpos brilla por su ausencia; es decir, los medios mayoritarios muestran corporalidades coherentes con la supuesta continuidad natural entre cuerpo (genitalidad), género y deseo sexual (Enguix y González, 2018: 5). En relación con esto, Pham (2016: 1) afirma: «La celebración cultural de la heterosexualidad como el estándar aceptado domina las principales instituciones sociales y penetra los mensajes sexuales culturales» ${ }^{4}$. De hecho, Holtby (2010: 17) remarca la invisibilidad del sexo entre mujeres en los medios de comunicación. Cook et al. (2013), por su parte, encuentran que en las 11 novelas con protagonistas lesbianas que analizan como transmisoras de roles y modelos, los resultados muestran que, aunque algunas emociones y comportamientos reflejados resisten los estereotipos de género tradicionales, otras emociones y comportamientos los refuerzan, incluidos los esquemas heterosexuales tradicionales. Pero también los cuerpos con diversidad funcional, o aquellos que no encajan en los cánones de belleza establecidos, son masivamente invisibilizados. Enguix y González (2018: 8) destacan que no existe una diversidad real de belleza femenina en la prensa gráfica y que, además, los modelos

4. Todas las traducciones son de las autoras. 
de belleza femenina más transgresores respecto a las normas de género (mujeres musculadas, andróginas, transgénero, etc.) generan extrañeza y rechazo entre las mujeres consultadas en su estudio (Enguix y González, 2018: 24-25). Todos estos datos inducen a repensar las industrias culturales como parte de la maquinaria biopolítica (por utilizar el término foucaultiano), de producción de cuerpos normativos; es decir, cuerpos heteronormativos y patriarcales, algo que resulta muy relevante si tenemos en mente que, tal y como señalan Enguix y González (2018), la corporalidad transciende su dimensión material interrelacionándose con los significados de género, formando de esta manera la base misma de nuestra identidad, así como el dispositivo que vehicula nuestras relaciones sociales.

No obstante, también encontramos ejemplos que resisten al orden sexual heteropatriarcal imperante. Por un lado, hay estudios que sugieren que los contenidos de los medios LGTB son más diversos e igualitarios que los contenidos de los medios dominantes (Milillo, 2008) y, por otro lado, parece que la sexualidad de ciertos colectivos (el colectivo LGTB y en especial el colectivo lésbico, así como el colectivo feminista) no se ve tan afectada por estos valores hegemónicos (Hammers, 2008; Schick et al., 2008; Holtby, 2010; Agirre, 2014), con lo cual cabría rescatar la capacidad transgresora que otorga la teoría queer al ámbito sexual.

\section{Metodología}

A través de la revisión de la literatura realizada se han detectado algunos vacíos que, a su vez, han generado líneas de investigación de interés para el presente estudio. Por un lado, como se ha mencionado anteriormente, cabe mencionar la relativa escasez de estudios en nuestro contexto que aborden cuestiones relativas con la sexualidad, en concreto, la insuficiencia de investigación respecto al impacto de la ideología feminista en dicho ámbito (una ideología indispensable en relación con la voluntad de cambio del orden heteropatriarcal actual de las relaciones de poder), así como la hegemonía de estudios heterocentrados. De todos estos debates, así como de las lagunas identificadas, surgen las preguntas de investigación que guían el presente estudio: ‘afectan los contenidos de las industrias culturales a la sexualidad de las personas de ideología feminista que componen la muestra? Si es así, ¿en qué cuestiones? ¿Existen diferencias entre los distintos colectivos estudiados en relación con su género y con su orientación sexual? ¿Qué impacto tiene la ideología feminista al respecto? Por tanto, los objetivos planteados son los siguientes:

- Analizar qué rol juegan los contenidos patriarcales y heteronormativos de las industrias culturales mayoritarias en la vivencia de la sexualidad de las personas participantes.

- Realizar una comparación entre los distintos grupos sexogenéricos definidos.

- Examinar el impacto de la ideología feminista que comparten las personas consultadas en relación con el rol de los medios de comunicación en su sexualidad. 
En aras de responder a estas preguntas, se ha escogido como universo objeto de estudio a personas de autoidentificación feminista sexualmente activas de cualquier género y de cualquier opción sexual que sean mayores de edad y que militen activamente en colectivos feministas, LGTBIQ+o en grupos de hombres a favor de la igualdad o en talleres de masculinidades. Para ello, tras realizar un listado de todas las agrupaciones feministas, LGTBIQ+ y de hombres a favor de la igualdad o que trabajen las masculinidades, pertenecientes a la CAE y a Navarra ${ }^{5}$, se ha contactado con ellas por correo electrónico, en su mayoría, y telefónica o presencialmente, en algunos casos. Cabe decir que en este universo donde nos movemos existen muchos grupos que, pese a estar muy activos, no se encuentran en ningún registro oficial y se ha accedido a ellos a través de la plataforma Facebook, tras realizar una búsqueda en las redes sociales y en internet.

Dado el carácter explicativo, interpretativo y particular de los objetivos, este artículo cuenta con un enfoque cualitativo que se ha llevado a cabo a través de entrevistas en profundidad semiestructuradas. Entre diciembre de 2016 y junio de 2017 se han realizado 29 a personas de entre 18 y 74 años de edad pertenecientes a 20 colectivos diferentes distribuidos por Hego Euskal Herria, que han sido analizadas a través de una estrategia de codificación tanto deductiva como inductiva, previamente diseñada y sistematizada, con el software de apoyo al análisis cualitativo ATLAS.ti. Se han creado tres grandes grupos basados en los códigos demográficos referentes a la identidad de género: mujeres cisgénero, hombres cisgénero y personas trans. En este último grupo, siguiendo a Coll-Planas (2012) y a Coll-Planas y Missé (2015), se ha incluido a todas aquellas personas que se identifican con un género diferente al asignado al nacer, independientemente de si han comenzado o no procesos de reasignación sexual, o de si tienen o no intención de hacerlo; también se ha incluido a aquellas personas que no se definen en parámetros binarios, es decir, ni como hombres ni como mujeres ${ }^{6}$. Por otro lado, se han elaborado cuatro grupos donde se ha clasificado la orientación sexual referida por cada persona: homosexual, heterosexual, bisexual o pansexual y asexual ${ }^{7}$.

5. Se han consultado el Registro de Asociaciones del Gobierno Vasco y de Emakunde, el Censo de Asociaciones de Mujeres de Navarra, la Guía Gay de España, la red AHIGE (Asociación de Hombres por la Igualdad de Género) y el listado de entidades federadas en FELGTB (Federación Estatal de Lesbianas, Gays, Transexuales y Bisexuales).

6. Para una discusión elaborada en torno al uso y al entendimiento de las categorías identitarias transexual y transgénero, consultar Coll-Planas y Missé (2015).

7. A efectos de poder observar a qué colectivo pertenece cada persona entrevistada, se ha asignado un código alfanumérico a cada una de ellas que contiene el número de entrevista, el género que han expresado, la orientación sexual que han expresado y su edad, respectivamente. Esta es la nomenclatura utilizada: $\mathrm{E}(\mathrm{n})$ : número de entrevista; M: mujer; $\mathrm{H}$ : hombre; OG: objetora de género; N: neutral; A: agénero; Q: queer; HT: hombre transexual; SM: socializada como mujer; $\mathrm{H}$ : heterosexual; G: gay; L: lesbiana; B: bisexual; P: pansexual; PH: prácticas homosexuales; A/ND: asexual o no definida; BO: bollera. Con lo cual, por ejemplo, E28SMBO34 significaría: entrevista número 28, socializada como mujer, bollera, de 34 años. Dada la gran diversidad y subjetividad de los múltiples sentires respecto al género 
A pesar de que se han creado diferentes grupos en base al género y a la opción sexual de las personas con una intención comparativa, cabe mencionar que en ningún caso se pretende realizar extrapolación alguna, y que nuestra intención no es extender las conclusiones ni a la población general ni a los grupos sociodemográficos creados. Por el contrario, nuestro objetivo es ahondar en las vivencias subjetivas, en las opiniones y experiencias de las personas entrevistadas, sabiendo que cada persona corporiza realidades simbólicas y materiales únicas, así como redes de opresión y de privilegio específicas. Lo interesante de la técnica utilizada es precisamente poder profundizar en estos significados y en estas nociones intrapersonales, gracias a la gran riqueza semántica y simbólica que ofrecen los discursos de todas y cada una de las personas entrevistadas. A continuación, pasaremos a exponer sus relatos ${ }^{8}$.

\section{El rol de las industrias culturales en la sexualidad de personas de ideología feminista}

Para dar respuesta al primer objetivo, dedicaremos el presente apartado a relatar cómo afectan este tipo de representaciones heterosexistas a la vida y al desarrollo sexual de las personas entrevistadas. En este sentido, hallamos posturas dispares en sus respuestas: algunas afirman que su sexualidad se ha visto trastocada de una u otra manera, mientras otras opinan lo contrario o no identifican que estos factores externos hayan podido incidir en su manera de experimentar las relaciones sexoafectivas.

Comenzando por el primer grupo, observamos que se pueden distinguir dos vertientes en sus respuestas, las cuales podrían clasificarse como externa e interna: por un lado, la que apunta a los modelos de atractivo externos como fuentes de deseo y atracción sexual (E4MB/P18, E7MH74, E9ML57, E12MB21, E15MH23, E16HH54, E18HH26, E20MH35, E29HH29) $y$, por otro lado, la que se refiere al rol de los medios en la autopercepción del propio cuerpo (E2HG23, E3HG23, E5HPH31, E13HH47, E19QL30, E20MH35, E28SMBO34), así como a las exigencias que derivan de los mandatos genéricos y de la heteronormatividad (E1MB25, E5HPH31, E9ML57, E10HH26, E26MA/ND28), cuestiones precisamente en las que nos centramos en este artículo, debido a que las propias personas participantes han puesto el foco en ello.

No obstante, cabe mencionar que, en relación con la que hemos calificado de vertiente externa, las personas entrevistadas que se han referido a esta cuestión han admitido que la apariencia física es importante en referencia a su deseo sexual, y que lo que les resulta atractivo en general es lo que concuerda con el

y a la orientación sexual, se ha mantenido lo expresado por cada persona en dichos códigos asignados, por respeto y por ofrecer una imagen más fiel de la realidad en este aspecto. Con fines meramente analíticos, nunca con ánimo reduccionista, se ha clasificado a las personas en tres grupos respecto al género, y cuatro respecto a la orientación sexual.

8. Varias de estas entrevistas se han realizado en euskera. Todas las traducciones son de las autoras. 
modelo hegemónico de belleza, puesto que, en relación con la función biopolítica de creación de cuerpos normativos, se nos enseña a considerar atractivos ciertos tipos de aspectos físicos y, en cambio, a rechazar otros.

Transitando hacia la vertiente interna, podemos advertir que, en las personas consultadas, la autopercepción del propio cuerpo suele derivar en complejos e inseguridades que causan un malestar que en última instancia deriva en el rechazo hacia una misma. Las siguientes palabras ilustran de manera breve y concisa las vivencias de las personas consultadas al respecto: "Yo no soy, digamos, el prototipo que un montón de personas buscan. Entonces, al final, durante un montón de tiempo, sí me ha [sic] mantenido un poco bajo de autoestima de, en plan de, "yo, estando así, igual no encuentro a alguien"” (E2HG23).

Por otro lado, también hay personas que reconocen en cierta manera el privilegio de entrar en el canon en este sentido. Una de ellas (E4MB/P18) cuenta que es consciente de que, si su cuerpo no fuese delgado o tuviese otras características físicas, seguramente no se habría involucrado sexualmente con las mismas personas ni con tantas. Otra entrevistada nos relata lo siguiente:

A ver, ¿sabes qué pasa?, pues que al final lo que yo siento es que yo no, eh..., que no salgo de la norma. O sea, al final soy una mujer que tiene una vulva, soy heterosexual, eh... No soy la más femenina del mundo, pero no soy hipermegamasculina... Entonces, ¿qué pasa?, dentro de todo esto, como socialmente mirando desde fuera cumplo... la norma, dentro de eso soy una privilegiada, y me siento cómoda. (E24MH36)

Estas palabras dejan en evidencia que, efectivamente, los cuerpos también revisten valor moral y estatus, y que aquellos cuerpos que más se aproximan a la normatividad (en términos de género y de belleza estándar) son los más valorados socialmente; por tanto, según se advierte en los discursos de las personas consultadas, la corporalidad también condiciona sus relaciones sociales situándolas en posiciones concretas de dominación y privilegio respecto a las demás personas. Si además tenemos en cuenta que la sexualidad es un ámbito destinado a la producción de cierta masculinidad y feminidad heteronormativa (Butler, 1990; Preciado, 2005), en el que la virilidad se muestra y el ego masculino se refuerza mediante el éxito en el desempeño heterosexual (MacKinnon, 1989; Corsi, 1995; Sakaluk et al., 2014), mientras que la valía femenina se mide a través de la apariencia física, vemos claramente que este éxito de los varones no se determina únicamente en base a la «destreza» en la relación sexual, sino que es especialmente dependiente del tipo de cuerpo con el que se realiza dicha práctica. Esto explicaría el hecho de que algunos entrevistados se hayan sentido presionados para ofrecer explicaciones ante el grupo de pares en las ocasiones en las que han mantenido relaciones con mujeres que no cumplían enteramente el canon.

Podemos concluir que varias de las personas entrevistadas admiten haber sentido y, en algunos casos, seguir sintiendo en su ámbito sexual estas presiones relativas a los mandatos de género dominantes y/o a la heteronormatividad, 
que, como se demuestra, están completamente unidas a los roles de género pertenecientes a los esquemas sexuales tradicionales. Unos mandatos que, en general, producen malestar, miedos y tensiones. Las vivencias de las consultadas hablan del castigo social que reciben las mujeres si salen de los patrones instaurados. Se trata de un castigo que, podemos concluir, es más severo en el caso de las mujeres, precisamente a causa de la doble moral sexual que establece la división entre mujeres buenas y malas (y su correlato de mujeres puras y putas), que rechaza comportamientos sexuales en las mujeres que en los hombres glorifica, como el tener múltiples relaciones sexuales con distintas personas o ser sexualmente activa y tener fuertes deseos sexuales (Impett y Peplau, 2003; Dworkin y O'Sullivan, 2005; Meston y O'Sullivan, 2007; Tolman et al., 2007; McCabe et al., 2010; Weinberg et al., 2010; Ménard y Cabrera, 2011; Vannier y O'Sullivan, 2011, 2012; Sakaluk et al., 2014). Por tanto, podemos afirmar que, aunque en ambos géneros normativos existen presiones para encajar dentro de los esquemas de género establecidos, estas exigencias son más severas y virulentas para las mujeres, por lo menos en las relaciones heterosexuales. En clara sintonía con las corrientes queer y el pensamiento postmoderno (Butler, 1990; Solá y Urko, 2014), una participante (E1MB25) finaliza su relato diciendo que, con el tiempo y mucha reflexión, todo esto se comienza a deconstruir, pero ello también sugiere que a las edades en las que en general las personas se inician en las relaciones sexuales se llega con una fuerte carga de heteronormatividad y patriarcado a la espalda. Otra respuesta interesante a la pregunta de si la representación cultural de los distintos cuerpos afecta en la vida sexual propia, nos la dejan las siguientes palabras, refiriéndose a la heterosexualidad obligatoria $^{9}$, que también de esta manera se fomenta:

Al final tú..., de pequeña, en la adolescencia, cuando tu identidad sexual se está definiendo, parece que en vez de apostar por lo que te gusta tienes que descartar algunas cosas. ¿No? Pues..., en vez de decir, no sé, eh... probaré con los chicos, pues no me gusta, entonces pum. No. Pero tienes que probar. O sea, como que... la misma sociedad te empuja: "A ver. Prueba esto por si acaso..." y si no te gusta, ya tiras por otro lado. Pero prueba. ¿¿No? Que estás obligada a vivir, eh..., y muchas veces con el trauma que eso puede suponer, eh, o sea, y qué consecuencias... psicológicas puede producir. (E26MA/ND28)

Asimismo, merece la pena recoger las siguientes líneas, dada su claridad en exponer algunas de las principales falacias sobre la sexualidad masculina. Sugieren que, efectivamente, la sexualidad es un terreno que cumple la función de reforzar la masculinidad (Corsi, 1995), lo que algunos de los hombres entrevistados viven como una presión y una obligación impuesta, cuyas consecuencias más inmediatas son sentimientos de malestar como la ansiedad y la angustia:

9. El término heterosexualidad obligatoria define la heterosexualidad como un régimen político en el que se basa el sistema de género, cuya reproducción no es una opción, sino una de las principales normas de la sociedad patriarcal (Rich, 1983). 
Yo soy hombre, y tengo que ser fuerte, el que no falla y, y... el que no puede sentirse mal, entonces es como... eh... una presión a no fallar, una presión, eh... eh..., no sé cómo decirlo, de ser satisfactorio para la otra persona o así, ¿no? [...] un miedo, eh... que el tiempo o... sea insuficiente, ¿no?, insuficiente... sí. A no rendir lo suficiente, no sé cómo decirlo [...]. Porque, claro, si no soy bueno, igual no soy, eh... lo suficientemente hombre, ¿̨no?, un rollo así, sí. (E10HH26)

De este párrafo se desprenden muchos mandatos y algunos mitos de lo que debe de ser la sexualidad masculina, sobre todo la exigencia de proporcionar placer y la creencia de que la calidad de la relación se mide proporcionalmente con el tiempo que dura el acto. Un hecho cuanto menos curioso nos viene de la mano de dos hombres (E10HH26 y E18HH26), quienes dicen que han llegado a fingir no haber tenido orgasmo, por esa presión implícita de tener que resultar satisfactorio para la(s) otra(s) persona(s) en relación muchas veces con la duración del acto. Por el contrario, prácticamente la mitad de las personas participantes afirma haber fingido orgasmos alguna vez, y la principal motivación para este fenómeno es no dañar los sentimientos o la autoestima de la(s) otra(s) persona(s), algo que concuerda con los resultados de otros estudios centrados en las mujeres (Goodman et al., 2017; Hite, 1976) y que vendría a confirmar esta presión que sienten algunas mujeres para no dañar el ego o la autoestima del varón en términos sexuales (MacKinnon, 1989). Volviendo a la cita, en la última frase podemos observar que se establece una fuerte unión entre masculinidad y potencia sexual, algo que, como hemos visto, además de ser congruente con los roles de género tradicionales relativos a la sexualidad, ha sido teorizado por autores como Corsi (1995).

Con todo lo expuesto hasta el momento, no parece arriesgado repensar las industrias culturales como parte de la maquinaria biopolítica destinada a producir cuerpos normativos en términos de género y de sexualidad. En la misma línea, la ya mencionada Sara Ahmed (2017), en una relectura queer y postcolonial, teoriza sobre el poder como un ente direccional que dirige a los cuerpos en unas orientaciones predeterminadas que en nuestro contexto sociocultural están marcadas por una heteronormatividad naturalizada, con lo cual no resulta complicado situar a las industrias culturales y sus representaciones cisheteronormativas como agentes directivos del biopoder. Estas ideas se refuerzan a base de testimonios que afirman el papel que han desempeñado las distintas imágenes, ideas y prejuicios recibidos sobre sexualidad, en especial aquellos derivados de la pornografía de masas en la construcción de la subjetividad sexual de algunas personas entrevistadas, sobre todo definiendo las primeras experiencias sexuales:

[...] esa es nuestra introducción al sexo, y en gran medida también los modelos que..., pues eso, los modelos que hemos tenido [...] yo recuerdo, eso, igual los vídeos porno que veíamos de pequeños [...] buscábamos ahí nuestros referentes $[\ldots]$ en mi vida personal mi introducción al sexo se ha basado mucho en eso. (E10HH26) 


\section{La subversión LGTBIQ+}

Tal y como hemos podido observar, sin embargo, la incidencia de las representaciones mediáticas no se produce de la misma manera entre los distintos colectivos participantes. Existen diferencias que en última instancia apuntan a que las personas que se sienten menos influenciadas por estos contenidos son aquellas que más se alejan de corporizar un estilo de vida cisheteronormativo. De hecho, de aquellas personas que opinan que su manera de desenvolverse sexualmente no se ha visto afectada por influencias externas, salvo una, el resto pertenece al colectivo LGTBIQ+ (E11ML/B20, E6OGL55, E17AB20, E21MH23, E25HTB50). Las dos primeras no saben realmente ofrecer una razón o una explicación a su respuesta, únicamente responden que no creen que los medios hayan influido en su vida sexual. El hecho de que ambas se identifiquen como lesbianas y que una de ellas, además, esté incluida en el colectivo trans según los parámetros de nuestro estudio, puede que no sea casual, ya que, al no estar tan representadas en los medios, tampoco cuentan con tantas referencias ni modelos establecidos. La relectura de los medios de comunicación y de las industrias culturales como entidades biopolíticas y direccionales orientadas a producir cuerpos y sujetos cisheteronormatvos nos ofrece los porqués de esta cuestión, situando a las identidades y a las sexualidades disidentes en cierta manera fuera de su campo de actuación, es decir, son cuerpos que se erigen como una contrasexualidad resistente que no se articula como hombres o mujeres, sino como cuerpos que renuncian a identidades sexuales cerradas y biológicamente predeterminadas (Preciado, 2002), por lo que se podría entender que se encuentran en cierto sentido fuera del aparato biopolítico heteronormativo. Para ahondar en esta hipótesis explicativa, conviene rescatar la polémica frase formulada por Monique Wittig (1992a: 57): «Las lesbianas no son mujeres». Según esta autora, pionera como hemos dicho en definir la heterosexualidad como un sistema social totalizador, en un desmantelamiento ontológico de las categorías sexuales, las lesbianas no son mujeres, ni en términos sexuales, ni económicos, ni políticos, ni ideológicos, porque «la mujer» tan solo adquiere significado cuando está al servicio del régimen heterosexual. Por tanto, como bien señalan Preciado (2005: 115-116) y Córdoba (2005: 38), la heterosexualidad es para Wittig una estructura monolítica, cerrada y totalizante, donde no existen fisuras posibles. La lesbiana, en cambio (y por extensión otras sexualidades e identidades no normativas), en una ruptura tajante con la dominación heterosexual, sería aquella que se encuentra en una exterioridad política absoluta, representando la libertad, mientras que la heterosexualidad representaría la sujeción. A pesar de que la teoría queer se oponga a esta división tan tajante, también entiende la disidencia sexual en términos de subversión y ruptura respecto a la norma sexual dominante, y algunos testimonios de las personas entrevistadas también parecen comprender su propia identidad en un sentido wittiguiano como algo diferenciado y liberador: «Mi rebeldía hace que... que no me afecte personalmente» (E25HTB50); «Ahora estoy un poco más libre, quiero decir, ya yo soy yo. Yo me identifico como quiero y yo cojo 
los roles que quiero" (E17AB20). Por el contrario, los colectivos que gozan de hegemonía, como las personas cisheterosexuales, son los que más presión sufren por corporizar el canon (Martínez, 2001, citada en Esteban, 2013: 81-82), así como los que mayormente comparten la mirada cisheteronormativa, intrínseca al habitus, a la hora de interpretar los discursos corporales, dado que su propia identidad forma parte de las nociones normativas interiorizadas y naturalizadas. Esto les proporciona cierto estatus y privilegio social y moral respecto a las sexualidades no normativas, es decir, un espacio de confort muy difícil de abandonar debido a la fuerte presión social que existe para acatar la norma y la gran amenaza de sanción social en caso de resistirla. En palabras de Ahmed (2007: 46): «[... ] abandonar un camino trillado [...] puede suponer abandonar un sistema de apoyo", es por ello por lo que resulta tan difícil zafarse de la presión social (muchas veces inadvertida) para acatar la norma cisheterosexual.

Así, también los sujetos no normativos revisten un gran significado sociosimbólico que transciende la dimensión material del cuerpo, que desde una lectura normativa parece actuar como mecanismo para salvaguardar el orden social, representando todo aquello que es negado y vilipendiado y que en última instancia puede crear hasta incomprensión y rechazo dada su transgresión social (Enguix y González, 2018: 18). Dicho de otro modo, las pocas representaciones mediáticas y negativas (victimizantes, paternalistas, estereotípicas, etc.) de las sexualidades disidentes actuarían también como parte del mecanismo biopolítico de la producción de cuerpos heteronormativos, constituyéndose a modo de reflejo de todo aquello que las personas cisheteronormativas podrían llegar a ser en caso de "desvío", como una imagen grotesca del propio ser que comprometería el espacio habitable, así como la capacidad para desarrollar una «buena» vida. Otra posible explicación añadida al hecho de que estas personas de la muestra no consideren que su sexualidad se ha visto afectada por las representaciones culturales heteronormativas es que las pocas referencias con las que cuentan estos colectivos en sus propios medios transgreden ciertos parámetros ofreciendo modelos más positivos y diversos (Milillo, 2008).

En cuanto al rol de las industrias culturales en la autopercepción del propio cuerpo, llama la atención que tan solo una persona de las siete que reconocen este hecho sea una mujer cisgénero, mientras que cuatro se han identificado como hombres cisgénero y el resto corresponde a la clasificación de personas trans. Y es que todas las personas que se han referido a esta temática reconocen que las presiones y las exigencias estéticas son mucho mayores entre las mujeres que entre los hombres. Además, parece que este hecho incide especialmente entre los hombres cuya práctica mayoritaria es homosexual, los cuales se han visto especialmente afectados en la autopercepción del propio cuerpo. Puede que esto sea porque las cuestiones estéticas se han fomentado en mayor medida entre este colectivo, muy dirigido frecuentemente a una cultura de consumo gay, denominado dolcegabanización por Preciado (2005: 111), estereotípicamente ligada a la metrosexualidad que innegablemente existe dentro del mercado capitalista, lo cual puede conllevar que las presiones estéticas en este colectivo sean también mayores que en otros colectivos. 
Por otro lado, las mujeres mencionan frecuentemente la configuración de los cuerpos que consideran sexualmente atractivos como uno de los mayores efectos de los medios en su sexualidad, pero, teniendo en cuenta que la construcción de la sexualidad hegemónica se basa más en la cosificación femenina que en la masculina, esto resulta un tanto sorprendente. Por el contrario, ninguna persona trans ha hecho referencia a esta cuestión, algo que podría ir de la mano de la invisibilización sistemática que sufren estos cuerpos en los medios mayoritarios.

\section{La toma de conciencia feminista}

Sara Ahmed (2017) teoriza sobre la construcción de la subjetividad feminista en términos de alienación respecto al conocimiento previo sociosimbólico principalmente recibido en el seno de la familia y que resulta afín a la noción de habitus de Bourdieu $(1979,1980)$. Es decir, adquirir una ideología feminista conlleva, según dicha autora, un rechazo del "camino trillado» o de las creencias y de los valores interiorizados durante la socialización, los cuales suelen ser congruentes con la normatividad hegemónica que reaparece ante la subjetividad feminista como socialmente injusta y perpetuadora de las relaciones de poder. En este sentido, Ahmed entiende el feminismo como una experiencia fallida en la adquisición e interiorización del sistema de género. De los discursos de las personas entrevistadas se extrae que, en línea con esta argumentación sobre la identidad feminista, dicha manera de percibir el mundo causa un impacto notable respecto a la influencia mediática en la sexualidad: por un lado, permite generar una toma de conciencia respecto a los contenidos mediáticos patriarcales y heteronormativos, así como una actitud crítica y una voluntad de cambio al respecto, y, por otro lado, también parece que fomenta cierta resistencia a la influencia de estos contenidos.

En relación con la toma de conciencia, en resumidas cuentas, las personas consultadas opinan que en las industrias culturales mayoritarias imperan la hipersexualización y la cosificación del cuerpo de las mujeres, los cánones de belleza imposibles, la gordofobia mediática y una castración de la diversidad real existente, de manera que los debates más amplios que se han generado desde los distintos feminismos respecto a esta temática pueden verse reflejados en sus testimonios. Desde una clara conciencia feminista, a ninguna de las personas entrevistadas se le pasa por alto que el cuerpo de la mujer "es un terreno... de reflejo todavía muy potente de las ideas... machistas» (E16HH54). Esta frase resulta interesante en tanto que expone claramente que el cuerpo material reviste un gran significado simbólico imbuido a su vez en fuertes relaciones de poder, lo cual conforma la inteligibilidad de los cuerpos en base al orden social dominante y a los mensajes culturales que lo fomentan. Este entrevistado no habla del cuerpo femenino como un ente orgánico y material destinado a llevar a cabo ciertas funciones vitales, sino como un soporte discursivo privilegiado en el que se inscribe la dominación masculina imperante a través de la corporeidad de las nociones culturales respecto a la feminidad y la masculinidad tradicionales. Así, se deja al descubierto una de 
las premisas fundamentales del denominado feminismo neomaterialista (Birke, 2000; Hird, 2004; Tuana, 2008; Hekman, 2008), esto es, el cuestionamiento de la dicotomía entre naturaleza y cultura, además de sus correlatos entre materia (cuerpo) y discurso, y sexo (cuerpo) y género, dada su indivisibilidad y mutua interdependencia. Esto se traduce en que los significados culturales de género y sexualidad intersectan con y en el cuerpo material creando sujetos que no solo reproducen, por ejemplo, ciertos ideales de belleza neutros e insignificantes, sino todo un sistema cultural de creencias y valores regidos por el sistema heteropatriarcal e imbuidos en valor moral (Enguix y González, 2018). En este sentido, la mayoría de las personas entrevistadas coincide en que los medios ofrecen una imagen del cuerpo de las mujeres hipersexualizada y cosificada. Expresiones que predominan en sus discursos, tales como «objeto total» (E1MB25), «muy explotado sexualmente» (E11ML/B20), «mujer florero» (E7MH74) u «objeto sexual» (E5HPH31) denotan este hecho. Y tal vez el que muchas de ellas mencionen la publicidad a la hora de hablar en torno a esta temática hace que expongan de forma clara que esta manera de representar el cuerpo femenino tiene muchas veces fines comerciales, lo que demuestra una vez más la unión existente entre capitalismo y heteropatriarcado ${ }^{10}$.

Además, las personas consultadas ponen de manifiesto el carácter estereotipado de estas representaciones, las cuales deben de cumplir con un canon de belleza preestablecido «irreal y muy... muy, muy artificial» (E12MB21) y «desnaturalizado» (E4MB/P18). Las siguientes líneas expresan muy acertadamente la idea que se quiere transmitir:

Se establece, eh... una serie de tipos de cuerpos, mm... pasando por, eh... totalmente por alto la, la diversidad real que existe en los cuerpos de las personas, y, y... pasando totalmente por alto lo que se, lo que puede ser más saludable en una persona. Te venden como interesantes unos tipos de cuerpo, «X» tipos de cuerpo, $\mathrm{y} . . . \mathrm{y}$ hay gente que... que lo interioriza y se acompleja de tal forma que hace cualquier cosa para intentar conseguir ese tipo de cuerpo. Eso puede ser desde un cuerpo muy delgado hasta un cuerpo con curvas, que si no las tienes puedes querer operarte o lo que sea para tenerlas, y, eh..., al final, el establecer unos tipos de cuerpo muy concretos como... como interesantes o válidos, es una forma de controlar, eh... masivamente a... en este caso a las mujeres, y de... de minar también su confianza, ¿sabes? (E3HG23)

A través de estas palabras se hace mención también a los efectos que puede causar en las personas establecer estos cánones de belleza prácticamente imposibles de alcanzar, que se resumen en complejos que efectivamente pueden acarrear problemas de salud, tal y como demostraban los estudios de Cahill y Mussap (2007) y de Noriega (2012).

Muchas personas participantes afirman que pese a que, en el caso de los hombres, las exigencias estéticas son cada vez mayores, todavía están muy lejos

10. Heidi Hartmann (1979) expuso magistralmente esta unión en su aclamado artículo «The unhappy marriage of marxism and feminism». 
de acercarse a las de las mujeres, y es que, además, los cuerpos femeninos no se representan tan solo como objetos sexuales, sino como objetos sexuales dirigidos al placer masculino. Unido a esto, otra entrevistada (E4MB/P18) comenta que las exigencias femeninas derivan precisamente de los requisitos que los varones les imponen. Estas formulaciones recuerdan bastante a las referidas por autoras rerpresentantes del feminismo radical como MacKinnon (1989) o Millett (1970), al remarcar el carácter androcentrista de la sexualidad. En cuanto a los hombres, las personas entrevistadas opinan que se les representa de una manera totalmente contraria, manifestando que existe un gran desequilibrio entre la manera de representar los cuerpos masculinos y los femeninos que reproduce férreos valores heteropatriarcales:

Bueno, pues que al final es, eh... representativo de las dicotomías que hemos mencionado antes. O sea, quiero decir, em $[s i c]$... la manera en la que construimos los cuerpos estéticamente también está directamente unida luego..., pues al modo en que se desarrollarán esas relaciones sexuales, o... o al modo en que se desarrollarán esos objetivos reproductores, o lo que sea, ¿̨no? [...]. Eh..., o sea, es un demostrativo del poder..., o sea, muy grande, eh... Bueno, no el propio hombre, sino esa representación de ambos. Y bueno, patriarcal, y... e injusto. Hay un gran desequilibrio entre los dos cuerpos. (E5HPH31)

En este sentido, cabe destacar una reflexión interesante de otra persona participante (E8NH47), quien dice que el cuerpo del hombre se representa «conjuntamente con el pensamiento", mientras que el de la mujer, como venimos diciendo, se retrataría como un mero objeto: «no tiene personalidad, está anulada. Es un mero objeto» (E1MB25). Como podemos comprobar, según los testimonios de nuestras confidentes, la representación mediática de los cuerpos se basa en los roles de género tradicionales adjudicados a las mujeres y a los hombres y, por tanto, resulta congruente con estudios previamente mencionados que afirman estos supuestos (Furnham y Bitar, 1993; Díaz et al., 2010; Ménard y Cabrera, 2011; Carretero, 2014; Gamble, 2016). Según la investigación llevada a cabo por Enguix y González (2018: 10-12), son precisamente las mujeres hipersexualizadas y cosificadas los modelos femeninos que mayor rechazo crean entre las mujeres participantes en su investigación, por considerarlos constructos hechos por y para el espectador masculino. Estas mismas consideraciones y reflexiones son las que llevan a generar verdadero rechazo y confrontación también entre nuestras entrevistadas, lo cual puede verse intensificado gracias a la ideología feminista que poseen y cuyo último fin es reivindicar un cambio radical en la situación actual de relaciones de poder (Ramazanoglu, 1989: 8).

Aunque resulta innegable que los cuerpos de los hombres tienen más margen que el de las mujeres, en tanto que las presiones derivadas de incumplir el canon son menores, no hay duda de que ambos cuerpos siguen siendo de una manera determinada. Nuestras confidentes opinan que existe una especie de castración mediática de la diversidad, en el sentido de que los cuerpos no normativos no se representan (entendiendo por no normativo todo aquello que escapa a la lógica heterosexual, al binarismo entre hombre y mujer y a su 
representación estereotipada, a lo que se entiende por (dis)capacidad y a los cánones de belleza). Opinan que la diversidad está totalmente invisibilizada, como si no existiera, que no se valora, y que en los exiguos casos en los que obtiene presencia es con una intencionalidad totalmente política. Hay quien añade que incluso en estas últimas circunstancias se presenta a estos cuerpos de manera victimizada y paternalista.

De todas estas cuestiones se extrae que, además, a aquellas personas que no encajan en los cánones de belleza dominantes o que no cumplen con otros requisitos de la normatividad y que, por tanto, están invisibilizadas, en cierto modo se les coarta su derecho a disfrutar de la sexualidad. Así, se dejan de considerar seres sexuados y en ocasiones se infantilizan, sobre todo en el caso de la diversidad intelectual. Esto no pasa desapercibido a algunas personas entrevistadas, que muestran su clara oposición al respecto:

[...] es cierto que son cuerpos asexuales, totalmente, o sea, entre ellos y ellas pueden sexualizarlo $[s i c]$ y tener relaciones, pero para esta sociedad es como "¡mira qué majico! [sic]». Y ya primero se victimiza a la persona, bueno, se vulne [sic], se vulnerabiliza [sic], de que entonces ya le quitas todo el carácter sexual o erótico de..., pues no, no es un cuerpo deseable, tanto intelectual como físico, o sea, eso es cierto. (E18HH26)

En lo referente a la diversidad en las vivencias de la identidad de género o en la orientación del deseo, un entrevistado opina que todos aquellos cuerpos que no mantienen la coherencia socialmente impuesta entre sexo, género y orientación sexual, «si salen es... forzado, y... y como en un contexto bastante... desnormalizado $[s i c]$, no sé. Como... un personaje peculiar, ¿̇no?» (E10HH26). En este sentido, de los testimonios de varias personas entrevistadas que se refieren a cómo se representa la pluma gay en televisión, a la victimización de ciertos tipos de cuerpos o al total acaparamiento de la cisheteronormatividad en los medios de referencia se puede concluir que solo se representan positivamente aquellos cuerpos que concuerdan con el género lineal ${ }^{11}$. Este hecho fomenta la organización dicotómica jerárquica y excluyente que rige la sociedad occidental, puesto que deja totalmente invisibilizado todo lo que se encuentra en los márgenes. Esto, a su vez, impide que se creen nuevos imaginarios colectivos más inclusivos y tolerantes.

Otro aspecto que señalan algunas entrevistadas, refiriéndose a los cánones de belleza y en especial a la exigencia de la delgadez, es la poca y negativa presencia de los cuerpos gordos en los medios. Hay quien incluso llega a insinuar que los medios realizan una especie de apología de la anorexia.

Por otra parte, varias de las personas entrevistadas no dudan en considerar la pornografía tradicional como una fuente importante de educación sexual

11. Signe Bremer (2013: 336) denomina "género lineal» a una secuencia de acciones en la que se asume que el cuerpo material de una persona, su sexo legal, su identidad de género, su expresión de género, su deseo sexual, sus formas de reproducción, su estatus parental y familiar, y su muerte, apuntan en una misma dirección a través de una línea recta. 
y destacan su relevancia como transmisora de valores heteropatriarcales y de estereotipos. Indagando más en las opiniones existentes acerca de la pornografía, nos encontramos con que algunas personas entrevistadas opinan que la pornografía tradicional resulta surrealista, coitocéntrica e incluso violenta, y dicen además que cosifica a la mujer, aparte de generar una relación de poder asimétrica. Todas estas cuestiones concuerdan con la literatura previa en la temática, que, como hemos visto, muestra precisamente que la pornografía mayoritaria efectivamente es una escuela de sexualidad heteropatriarcal que no favorece ni la igualdad de género, ni la diversidad sexual, ni siquiera una sexualidad saludable y beneficiosa, a través de unas representaciones estereotipadas que erotizan la desigualdad y la cosificación femeninas, así como ciertas conductas de riesgo muy perjudiciales (Dworkin y MacKinnon, 1988; Bridges et al., 2003; Hald et al., 2010; Foubert et al., 2011; Arrington-Sanders et al., 2015; Braithwaite et al., 2015; Wright, Sun et al., 2015; Wright, Tokunaga et al., 2015; Morales, 2016).

Todas estas cuestiones generan que, entre las personas entrevistadas, se advierta una voluntad de cambio, resistencia y subversión que, a su vez, no está exenta de contradicciones internas que derivan sobre todo de la dificultad de la materialización práctica de los principios feministas. Los testimonios más reveladores en relación con esta cuestión dejan de manifiesto la capacidad que tienen algunas personas para identificar la autopercepción negativa de su cuerpo como algo socialmente impuesto que desean combatir, ya que no acarrea más que sufrimiento e incluso resulta incoherente con sus ideas. Pero, al mismo tiempo, muestran la gran dificultad de aunar teoría y práctica cuando las nociones de belleza y su importancia están tan arraigadas. Si nos reafirmamos en la idea de que estas representaciones normativas forman parte del conocimiento previo o de la herencia sociosimbólica recibida en el seno de una sociedad heteropatriarcal, parece lógico que exista dicha dificultad para el cambio, puesto que, según Bourdieu (1980: 86), el habitus nos condena a una especie de reproducción de lo mismo, ya que es duradero dado su profundo arraigo y resulta difícil o imposible de modificar. Por tanto, esta dificultad práctica combinada con una reorientación feminista relativa a la ideología podría dar cuenta de estas tensiones y contradicciones que se advierten en algunos relatos de las personas entrevistadas en relación con los intentos de subversión y resistencia:
Al final interiorizas muchas cosas y... a veces te das cuenta de que tienes deter- minadas inseguridades que eres capaz de identificar o que eres capaz de decir: «Eh, esta inseguridad es una... es una mierda, porque sé de dónde viene y sé que lo he interiorizao $[s i c]$, que esto no es válido en mi cuerpo» [...], pero, al final... dices: "Ya, pero es que no quiero que esté eso ahí», eso es porque te han enseñado, o sea, lo tienes tan metido que es como una especie de..., no sé, como un tumor ahí amarrao [sic] que no te lo puedes arrancar, es horrible, o sea, y... es difícil darle la vuelta. (E3HG23)

No obstante, también reconocen la labor que desde el activismo feminista se está realizando en este sentido a la hora de difundir otras imágenes y repre- 
sentaciones que enfrentan las categorías heteronormativas dominantes que dicotomizan los cuerpos, los géneros y los deseos. Un claro ejemplo de esto último es la postpornografía, la cual las personas consultadas distinguen claramente de la pornografía mayoritaria y que pretende subvertir y criticar la pornografía tradicional, apropiándose de ese espacio en cierto sentido privilegiado para reivindicar nuevas representaciones, nuevos placeres y nuevas identidades (Ares y Pedraz, 2011; Sutherland, 2012). De hecho, parece que la ideología feminista desempeña un papel importante en la menor influencia respecto a las mujeres cisgénero de la muestra, la mayoría de las cuales proviene de la militancia propiamente feminista, mientras que la mayor parte del resto de personas se encuentra integrada en colectivos activistas LGTBIQ+o en grupos de hombres a favor de la igualdad. El entendimiento del feminismo como una experiencia fallida en la interiorización del sistema de género (Ahmed, 2017), junto con la larga labor del activismo feminista en relación con la hipersexualización y la cosificación femeninas, podrían dar cuenta de la resistencia de las mujeres entrevistadas a la influencia de las exigencias estéticas respecto a la feminidad, puesto que, más allá de la materialidad, revisten significados de género que derivan de estas corporalidades. De hecho, el estudio de Enguix y González (2018: 10-12) muestra que las modelos hipersexualizadas y cosificadas no solo son las peor valoradas por las mujeres consultadas, sino que además no provocan autoidentificación alguna. El rechazo a los valores de género que las exigencias estéticas femeninas generan (objeto sexual, entrega al hombre, pasividad, etc.), en las cuales las mujeres feministas informantes no se ven en absoluto representadas, podría reforzar esta desidentificación y confluir con la reorientación de la que habla Ahmed (2017). Estas reflexiones se ven apoyadas por testimonios de varias mujeres consultadas que afirman haberse sentido influidas por los medios de una manera más positiva y empoderante a raíz de que han provocado una crítica y una reflexión feministas en torno a estas imágenes que muestran una realidad distorsionada y perjudicial, cuyo último impacto ha sido una mejor autopercepción del propio cuerpo (E24MH36); o discursos que explícitamente ponen en valor la reflexión y el trabajo en torno al feminismo y a sus valores, considerándolo la razón central de no sentirse influenciadas por las imágenes culturales que promueven los distintos medios (E12MB21).

\section{Conclusiones}

Esta investigación nos ha permitido acercarnos a las vivencias y a la percepción de las personas participantes sobre el rol que desempeñan los contenidos mediáticos heteropatriarcales en su sexualidad. Pero lo hemos hecho desde una perspectiva que la literatura previa en la temática no contempla suficientemente: por un lado, queriendo discernir el impacto de la ideología feminista al respecto y, por otro lado, ampliando el abanico generalmente muy heterocentrado a todo tipo de géneros y sexualidades, para ofrecer así una visión menos parcial de la realidad y poder averiguar si existen diferencias en relación con las categorías sexogenéricas. 
A través de las narrativas analizadas hemos podido confirmar que, independientemente de su autoidentificación con la ideología feminista, los mensajes y las representaciones heterosexistas de los medios culturales calan tan hondo que, efectivamente, afectan a la manera en que se desenvuelven sexualmente las personas que componen la muestra. En este sentido, podemos concluir que estos contenidos heteropatriarcales forman parte de la herencia sociosimbólica (habitus) que se recibe en nuestro contexto social, puesto que son estos tipos de cuerpos, y la dominación masculina y heterosexual que revisten, lo que viene largamente asimilando la mayoría del conjunto social como válido, normal y reconocible. De este modo se ha constatado que, de acuerdo con la literatura previa en la temática (por mencionar alguna: Ward, 2002, 2003; Kim y Ward, 2004; Giles, 2006; García y Martínez, 2008; Yao et al., 2010; Ménard y Cabrera, 2011; Noriega, 2012; Gamble, 2016; Morales, 2016), los ámbitos sexuales en los que las personas consultadas sienten que estos agentes externos han incidido son la autopercepción del propio cuerpo; las exigencias de los mandatos de género tradicionales, y, por último, la concepción de lo que es atractivo, sexual y erótico. Estas imágenes corporales, por tanto, rebasan los límites materiales del cuerpo creando imaginarios sociales, escalas morales, así como significados de género comunes que intersectan en la identidad de las personas entrevistadas, condicionando las relaciones sociales que generan (Enguix y González, 2018), provocándoles complejos e inseguridades, además de diversos conflictos, tensiones y malestares que provocan dificultades a la hora de enfrentarse a las relaciones sexuales.

Sin embargo, esta influencia o asimilación de los mensajes culturales mayoritarios no se produce de la misma manera entre los distintos colectivos sexogenéricos que abarca el estudio. Siguiendo las tesis foucaultianas y butlerianas sobre la posibilidad de subversión y transformación de las relaciones de poder (Foucault, 1979; Butler, 1990), hemos podido observar que, efectivamente, dentro del régimen mayoritario pero inestable que constituye la heterosexualidad, existe espacio para la resistencia, con lo cual hallamos grietas o puntos de fuga ante esta incidencia mediática aparentemente totalizadora e insalvable. En sintonía con los resultados de algunos estudios previos que se refieren al colectivo LGTBIQ+ en general (Agirre, 2014) y al colectivo lesbiano en particular (Hammers, 2008; Holtby, 2010), podemos concluir que las personas que más se alejan de corporizar una identidad cisheteronormativa y, por tanto, aquellas que mayor resistencia oponen a la asimilación de las convenciones sexogenéricas, son las que menos influenciadas se sienten por los contenidos culturales mayoritarios. Parece que, de acuerdo con Butler (1990, 1993), a pesar de que la heterosexualidad y su otredad vilipendiada constituyan ambas caras de una misma moneda, la disidencia sexual reviste un carácter subversivo dada su posición privilegiada desde los márgenes para desvelar la falacia de la cisheteronormatividad, posibilitando así la transgresión de los códigos culturales heteropatriarcales. Por otro lado, aplicando a este ámbito las teorizaciones de Wittig sobre la heterosexualidad y su radical desencialización de las categorías sexogenéricas (Wittig, 1992a, 1992b), también se podría concluir 
que la disidencia sexual conforma un espacio totalmente ajeno al orden heteronormativo que se rige en base a sus propias reglas, en un espacio de mayor libertad respecto al orden sexual heteropatriarcal. A su vez, aquellas personas que subvierten la heteronormatividad, al no estar tan representadas en los medios, tampoco disponen de tantas referencias ni de tantos modelos establecidos (Pham, 2016; Enguix y González, 2018), y sus propios medios cuentan con otro tipo de representaciones que, aun siendo minoritarias, fomentan valores más igualitarios que muestran mayor diversidad (Milillo, 2008). En este sentido, podríamos afirmar que, al no corporizar la identidad normativa que las industrias culturales están destinadas a producir, las personas LGTBIQ+ participantes quedan, en cierta manera, más al margen del influjo de ese biopoder mediático patriarcal y heteronormativo.

En cuanto al impacto que causa la ideología feminista, podemos afirmar que ofrece las herramientas para crear conciencia y generar actitudes críticas hacia el sexismo con el que se retratan los diversos cuerpos (o la absoluta ausencia de otros) y sus consecuencias, así como para identificar sus propios deseos como constructos socioculturales que derivan de una socialización muy concreta basada en los valores de una sociedad heteropatriarcal, incluso en ocasiones para subvertir ciertas expectativas basadas en los mandatos de género tradicionales. En relación con la toma de conciencia, algo que resulta muy notable es cómo los debates feministas en torno a la temática se reflejan en sus discursos y testimonios. En este sentido, podemos advertir las connotaciones antisexo de Dworkin (1981) y MacKinnon (1991) cuando las personas entrevistadas hablan sobre la pornografía mayoritaria y sus efectos, o los postulados del feminismo radical (Greer, 1970; Millett, 1970; Koedt, 1972; Firestone, 1973; Daly, 1978; Dworkin, 1981) cuando se refieren al carácter patriarcal y androcéntrico de la sexualidad que se fomenta a través de las industrias culturales. No obstante, las personas consultadas se sitúan más cerca de las nociones postmodernas y queer al advertir no solo la dominación masculina en los contenidos mediáticos, sino también relaciones de subordinación y privilegio que abarcan otros colectivos que corporizan múltiples opresiones. De este modo, además de cuestiones como la cosificación y la hipersexualización femeninas, en sus relatos también sobresalen las críticas hacia el acaparamiento cisheteronormativo y la falta de diversidad de género y sexoafectiva de los contenidos mediáticos, e incluso yendo más allá, la denuncia de la gordofobia o del capacitismo que se transmiten. Sea como fuere, no cabe duda de que reconocen en las industrias culturales la maquinaria biopolítica de producción de cuerpos normativos.

Esta toma de conciencia y la actitud crítica que genera la ideología feminista provoca una voluntad de cambio entre nuestras participantes referente al orden actual de las relaciones de poder imperantes, que en este caso se traduce, por ejemplo, en querer otorgar menos importancia a la apariencia física de los cuerpos. Consiste en una voluntad de llevar al terreno práctico sus valores feministas que en ocasiones generan escenarios complejos y contradictorios, dada la dificultad de aunar teoría y práctica en este sentido. Sin embargo, las vivencias de las personas entrevistadas sugieren, al igual que estudios previos (Schick et al., 2008), 
que, a pesar de estas dificultades, la ideología feminista desempeña un papel importante como motor de cambio y de transformación. Como ejemplo podríamos mencionar a las mujeres cisgénero provenientes de grupos feministas que parecen estar menos afectadas por los medios en relación con la autopercepción de su propio cuerpo. Esto puede deberse a que la ideología feminista provoque una desidentificación con los valores femeninos que transmiten estas imágenes, tal y como señalaban Enguix y González (2018), y a que la propia adquisición del posicionamiento feminista, en tanto que constituye una ideología que cuestiona todas las nociones normalizadas y naturalizadas, conlleve una alienación del habitus interiorizado (Ahmed, 2017), con lo cual las personas entrevistadas pertenecientes al activismo feminista están más empoderadas en este sentido.

\section{Referencias bibliográficas}

Abramson, Paul R. y Mechanic, Mindy B. (1983). «Sex and the media: Three decades of best-selling books and mayor motion pictures». Archives of Sexual Behaviour, 12(3), 185-206. <https://doi.org/10.1007/BF01542071>

AgrrRe, Amaia (2014). «La gestión de la sexualidad en parejas con ideología igualitaria: De la monogamia dada por sentada a la negociación». RIPS. Revista de Investigaciones Politicas y Sociológicas, 13(1), 87-101. Recuperado de <http://www.usc.es/ revistas/index.php/rips/article/viewFile/1666/1960>.

Ahmed, Sara (2017). Living a feminist life. Durham y Londres: Duke University Press.

Ares, Loreto y Pedraz, Sara (2011). «Sexo, poder y cine: Relaciones de poder y representaciones sexuales en los nuevos relatos pornográficos». Icono, 14, 9(3), 98-119. Recuperado de <https://icono14.net/ojs/index.php/icono14/article/view/59>.

Arrington-Sanders, Renata; Harper, Gary W.; Morgan, Anthony; Ogunbajo, Adedotun; Trent, Maria y Fortenberry, J. Dennis (2015). «The role of sexually explicit material in the sexual development of same-sex attracted black adolescent males». Archives of Sexual Behavior, 44(3), 597-608. <https://doi.org/10.1007/s10508-014-0416-x>

Birke, Lynda (2000). Feminism and the biological body. New Brunswick: Rutgers University Press.

Bourdieu, Pierre (1979). Distinction: A social critique of the judgement of taste. Cambridge: Harvard University Press, 1996.

- (1980). El sentido práctico. Buenos Aires: Siglo Veintiuno, 2007.

Braithwaite, Scott R.; Coulson, Gwen; Keddington, Krista y Fincham, Frank D. (2015). «The influence of pornography on sexual scripts and hooking up among emerging adults in college». Archives of Sexual Behaviour, 44(1), 111-123. $<$ https://doi.org/10.1007/s10508-014-0351-x>

Bremer, Signe (2013). «Penis as risk: A queer phenomenology of two Swedish transgender women's narratives on gender correction». Somatechnics, 3(2), 329-350. <https://doi.org/10.3366/soma.2013.0101>

Bridges, Ana J.; Bergner, Raymond M. y Hesson-McInnis, Matthew (2003). «Romantic partners' use of pornography: its significance for women». Journal of Sex and Marital Therapy, 29 (1), 1-14. Recuperado de <https://www.researchgate. net/publication/10957430_Romantic_partners\%27_use_of_pornography_Its_significance_for_women>. 
Butler, Judith (1990). El género en disputa: El feminismo y la subversión de la identidad. Barcelona: Paidós, 2007.

- (1993). Bodies that matter: On the discursive limits of «sex». Nueva York y Londres: Routledge.

Cahill, Sara y Mussap, Alexander J. (2007). «Emotional reactions following exposure to idealized bodies predict unhealthy body change attitudes and behaviours in women and men». Journal of Psychosomatic Research, 62(6), 631-639. <https://doi.org/10.1016/j.jpsychores.2006.11.001>

Carretero, Ana (2014). "Publicidad sexista y medios de comunicación». Revista CESCO de derecho de consumo, 10, 130-142. Recuperado de <https://www.revista. uclm.es/index.php/cesco/article/view/544>.

Сово, Rosa (2015). «El cuerpo de las mujeres y la sobrecarga de sexualidad». Investigaciones Feministas, 6, 7-19. $<$ https://doi.org/10.5209/rev_INFE.2015.v6.51376>

Coll-Planas, Gerard (2012). “"El circo de los horrores”: Una mirada interseccional a las realidades de lesbianas, gays, intersex y trans». En: Platero, Raquel (Lucas) (ed.). Intersecciones: Cuerpos y sexualidades en la encrucijada. Temas contemporáneos. Barcelona: Bellaterra.

Coll-Planas, Gerard y Missé, Miquel (2015). «La identidad en disputa: Conflictos alrededor de la construcción de la transexualidad». Papers, 100(1), 35-52. $<$ https://doi.org/10.5565/rev/papers.637>

Cook, Jennifer R.; Rostosky, Sharon S. y Riggle, Ellen D. (2013). «Gender role models in fictional novels for emerging adult lesbians». Journal of Lesbian Studies, 17 (2), 150-166. <https://doi.org/10.1080/10894160.2012.691416>

Córdoba, David (2005). «Teoría queer: Reflexiones sobre sexo, sexualidad e identidad. Hacia una politización de la sexualidad». En: Córdoba, David; Sáez, Javier y Vidarte, Paco (eds.). Teoría queer: Políticas bolleras, maricas, trans, mestizas. Madrid: Egales.

Corsi, Jorge (1995). "La construcción de la identidad masculina». En: Corsi, Jorge (ed.). Violencia masculina en la pareja: Una aproximación al diagnóstico y a los modelos de intervención. Buenos Aires: Paidós.

Daly, Mary (1978). Gin/ecology: The metaethics of radical feminism. Boston: Beacon Press, 1990.

Dempsey, J.M. y Reichert, Tom (2000). "Portrayal of married sex in the movies». Sexuality and Culture, 4 (3), 21-36. <https://doi.org/10.1007/s12119-000-1019-3>

Díaz, Paloma; Quintas, Natalia y Muñız, Carlos (2010). «Cuerpos mediáticos versus cuerpos reales: Un estudio de la representación del cuerpo femenino en la publicidad de marcas de moda en España». Icono, 14, 8(3), 244-256. <https://doi.org/10.7195/ri14.v8i3.237>

Dworkin, Andrea (1981). Pornography: Men possessing women. Nueva York: Plume, 1989.

Dworkin, Andrea y MacKinnon, Catharine A. (1988). Pornography and civil rights: A new day for women's equality. Minneapolis: Organizing Against Pornography, 1989.

Dworkin, Shari L. y O'Sullivan, Lucia (2005). «Actual versus desired initiation patterns among a sample of college men: Tapping disjunctures within traditional male scripts». Journal of Sex Research, 42 (2), 150-158. <https://doi.org/10.1080/00224490509552268> 
Enguix, Begonya y González, Ana María (2018). "Cuerpos, mujeres y narrativas: Imaginando corporalidades y géneros». Athenea Digital, 18(2), 1-31. $<$ https://doi.org/10.5565/rev/athenea.1956>

Esteban, Mari Luz (2013). Antropología del cuerpo: Género, itinerarios corporales, identidad y cambio. Barcelona: Ediciones Bellaterra.

Firestone, Shulamith (1973). La dialéctica del sexo: En defensa de la revolución feminista. Barcelona: Kairós, 1976.

Fithern, David L. (1996). Gay pornography as cultural object: Homosexual desire and the transmission of dominant ideology. Tesis doctoral. Recuperado de la base de datos ProQuest Dissertations and Theses (MM No. 18390) <https://spectrum.library. concordia.ca/3347/1/MM18390.pdf>.

Foubert, John D.; Brosi, Matthew W. y Bannon, Sean (2011). «Pornography viewing among fraternity men: Effects on bystander intervention, rape myth acceptance and behavioral intent to commit sexual assault». Sexual Addiction \& Compulsivity, 18 (4), 212-231. <https://doi.org/10.1080/10720162.2011.625552>.

Foucault, Michel (1976). Historia de la sexualidad. 1: La voluntad de saber. Madrid: Siglo Veintiuno, 1991.

- (1979). Microfísica del poder. Madrid: La Piqueta.

Furnham, Adrian y Bitar, Nadine (1993). «The stereotyped portrayal of men and women in British television advertisements». Sex Roles, 29(3-4), 297-310. <https://doi.org/10.1007/BF00289940>

Furnham, Adrian y Paltzer, Stephanie (2010). «The portrayal of men and women in television advertisements: An updated review of 30 studies published since 2000». Scandinavian Journal of Psychology, 51(3), 216-236. <https://doi.org/10.1111/j.1467-9450.2009.00772.x>

Gamble, Hilary (2016). From sexual media to unwanted hookups: The mediating influence of college students' endorsment of traditional heterosexual scripts, sexual selfconcept, and perceived peer norms. Tesis doctoral. Recuperado de la base de datos ProQuest Dissertations and Theses (UMI No. 10144162) <https://arizona.openrepository.com/handle/10150/621020>.

García, Nuria y Martínez, Luisa (2008). «La recepción de la imagen de las mujeres en los medios: Una aproximación cualitativa». Comunicación y Sociedad, 10, 111-128. Recuperado de <http://www.scielo.org.mx/scielo.php?script=sci_ arttext\&pid=S0188-252X2008000200005>.

Giles, James (2006). «Social constructionism and sexual desire». Journal for the Theory of Social Behaviour, 36 (3), 225-238. <https://doi.org/10.1111/j.1468-5914.2006.00305.x>

Goodman, Danya L.; Gillath, Omri y Haj-Mohamadi, Parnia (2017). «Development and validation of the pretending orgasms reasons measure». Archives of Sexual Behavior, 46(7), 1973-1991. <https://doi.org/10.1007/s10508-016-0928-7>

Greer, Germaine (1970). The female eunuch. Nueva York: Harper Collins Publishers, 2008.

Hald, Gert Martin; Malamuth, Neil M. y Yuen, Carlin (2010). «Pornography and attitudes supporting violence against women: Revisiting the relationship in nonexperimental studies». Agressive Behaviour, 36 (1), 14-20.

<https://doi.org/10.1002/ab.20328> 
Hammers, Corie J. (2008). «Making space for an agentic sexuality?: The examination of a lesbian/queer bathhouse». Sexualities, 11, 547-572. <https://doi.org/10.1177/1363460708094267>

Hartmann, Heidi (1979). "The unhappy marriage of marxism and feminism: Towards a more progressive union». En: SitTon, John F. (ed.). Marx today: Selected works and recent debates. Nueva York: Palgrave Macmillan, 2010.

Hekman, Susan (2008). "Constructing the ballast: An ontology for feminism». En: Alaimo, Stacy y Hekman, Susan (eds.). Material feminisms. Bloomington e Indianapolis: Indiana University Press.

Hicks, Stephen y Jeyasingham, Dharman (2016). «Social work, queer theory and after: A genealogy of sexuality theory in neo-liberal times». The British Journal of Social Work, 46, 2357-2373. <https://doi.org/10.1093/bjsw/bcw103>

Hird, Myra J. (2004). «Feminist matters: new materialist considerations of sexual difference». Feminist Theory, 5(2), 223-232. <https://doi.org/10.1177/1464700104045411>

Hite, Shere (1976). El informe Hite: Estudio de la sexualidad femenina. Barcelona: Plaza y Janés, 1977.

Holtby, Alixandra (2010). Reconstructing sex: Women having sex with women. Tesis doctoral. Recuperado de la base de datos Proquest Dissertations and Theses (MR No. 68725 <http://scholars.wlu.ca/etd/997/>.

Impett, Emily A. y Peplau, Letitia A. (2003). «Sexual compliance: Gender, motivational, and relationship perspectives». The Journal of Sex Research, 40(1), 87-100. $<$ https://doi.org/10.1080/00224490309552169>

KIM, Janna L. y WARD, L. Monique (2004). «Pleasure reading: Associations between young women's sexual attitudes and their reading of contemporary women's magazines». Psychology of Women Quarterly, 28 (1), 48-58. $<$ https://doi.org/10.1111/j.1471-6402.2004.00122.x>

Koedt, Anne (1972). "The myth of the vaginal orgasm». En: Jackson, Stevi y ScotT, Sue (eds.). Feminism and sexuality: A reader. Edimburgo: Edimburgh University Press, 1998.

MacKinnon, Catharine A. (1989). Hacia una teoría feminista del Estado. Madrid: Cátedra, 1995.

- (1991). «Pornography as defamation and discrimination». Boston University Law Review, 71, 1-21. Recuperado de <https://web.archive.org/web/20060914034910/ http://lic.law.ufl.edu/ hernandez/Women/Mackin.pdf>.

McCabe, Janice; Tanner, Amanda E. y Heiman, Julia R. (2010). «The impact of gender expectations on meanings of sex and sexuality: Results from a cognitive interview study». Sex Roles, 62 (3), 252-263. <https://doi.org/10.1007=s11199-009-9723-4>

Ménard, A. Dana y Kleinplatz, Peggy K. (2008). «Twenty-one moves guaranteed to make his thighs go up in flames: Depictions of "great sex" in popular magazines». Sexuality and Culture, 12 (1), 1-20. <https://doi.org/10.1007/s12119-007-9013-7>

Ménard, A. Dana y Cabrera, Christine (2011). "Whatever the approach, tab B still fits into slot A": Twenty years of sex scripts in romance novels». Sexuality \&. Culture, 15 (3), 240-255.

<https://doi.org/10.1007/s12119-011-9092-3> 
Meston, Cindy M. y O’Sullivan, Lucia F. (2007). «Such a tease: intentional sexual provocation within heterosexual interactions». Archives of Sexual Behavior, 36 (4), 531-542. <https://doi.org/10.1007=s10508-006-9167-7>

Morales, Paola (2016). "Realidades visuales que mitifican: Sexualidad heteronormativa en el porno "mainstream" y "girlfriendly" ". XII Congreso Español de Sociología, 30 de junio, 1 y 2 de julio. Recuperado de <http://fes-sociologia.com/ realidades-visuales-que-mitifican-sexualidad-heteronormativa-en-el-po/congresspapers $/ 3730 />$.

Milillo, Diana (2008) «Sexuality sells: A content analysis of lesbian and heterosexual women's bodies in magazine advertisements». Journal of Lesbian Studies, 12(4), 381-392. <https://doi.org/10.1080/10894160802278267>

Millett, Kate (1970). Politica sexual. Madrid: Cátedra, 1995.

Noriega, Andrea (2012). The conflation of health and beauty in advertising: A critical multimodal discourse analysis of three television commercials. Tesis doctoral. ISBN: 978-0-499-00495-6. Recuperado de <https://curve.carleton.ca/43b92323-2621467c-9574-92bf635174f8>.

Peter, Jochen y Valkenburg, Patti M. (2007). "Adolescents' exposure to a sexualized media environment and their notions of women as sex objects». Sex Roles, 56 (5-6), 381-395. <https://doi.org/10.1007/s11199-006-9176-y>

Pham, Janelle M. (2016). "The limits of heteronormative sexual scripting: College student development of individual sexual scripts and descriptions of lesbian sexual behavior». Frontiers in Sociology, 1 (7), 1-10. $<$ https://doi.org/10.3389/fsoc.2016.00007>

Platero, Raquel (Lucas) y Rosón, María (2012). "De "La parada de los monstruos" a los monstruos de lo cotidiano: La diversidad funcional y sexualidad no normativa». Feminismos, 19, 127-142. <https://doi.org/10.14198/fem.2012.19.08>

Preciado, Paul B. (2002). Manifiesto contrasexual. Barcelona: Anagrama, 2016.

- (2005). «Devenir bollo-lobo o cómo hacerse un cuerpo queer a partir de El pensamiento heterosexual». En: Córdoba, David; Sáez, Javier y Vidarte, Paco (eds.). Teoria queer: Politicas bolleras, maricas, trans, mestizas. Madrid: Egales.

Ramazanoglu, Caroline (1989). "Feminism as contradiction». En: Ramazanoglu, Caroline. Feminism and the contradictions of oppression. Nueva York: Routledge, 2003.

Rich, Adrienne (1983). "Compulsory heterosexuality and lesbian existence». En: SNItow, Ann; Stansell, Christine y Thompson, Sharon (eds.). Powers of desire: The politics of sexuality. New York: Monthly Review Press.

Sakaluk, John K.; Todd, Leah M.; Milhausen, Robin; Lachowsky, Nathan J. y Undergraduate Research Group in Sexuality (URGiS) (2014). «Dominant heterosexual sexual scripts in emerging adulthood: Conceptualization and measurement». Journal of Sex Research, 51, 516-531. <https://doi.org/10.1080/00224499.2012.745473>

Schick, Vanessa R.; Zucker, Alyssa N. y BAy-Cheng, Laina Y. (2008). «Safer, better sex through feminism: The role of feminist ideology in women's sexual wellbeing». Psychology of Women Quarterly, 32, 225-232. <https://doi.org/10.1111/j.1471-6402.2008.00431.x> 
Solá, Miriam y Urko, Elena (eds.) (2014). Transfeminismos: Epistemes, fricciones y flujos. Tafalla: Txalaparta.

Sutherland, Juan Pablo (2012). «Post/pornografía: géneros disidentes en el horizonte corporal». Nomadias, 16, 275-282. <https://doi.org/10.5354/0719-0905.2012.25024>

Tolman, Deborah L.; Kim, Janna L.; Schooler, Deborah y Sorsoli, C. Lynn (2007). «Rethinking the associations between television viewing and adolescent sexuality development: Bringing gender into focus». Journal of Adolescent Health, 40 (1), 9-16. <https://doi.org/10.1016/j.jadohealth.2006.08.002>

Tuana, Nancy (2008). "Viscous porosity: witnessing Katrina». En: Alaimo, Stacy y Hekman, Susan (eds.). Material feminisms. Bloomington e Indianapolis: Indiana University Press.

Vannier, Sarah A. y O'Sullivan, Lucia F. (2011). "Communicating interest in sex: Verbal and nonverbal initiation of sexual activity in young adults' romantic dating relationships». Archives of Sexual Behavior, 40(5), 961-969.

<https://doi.org/10.1007=s10508-010-9663-7>

- (2012). "Who gives and who gets: Why, when, and with whom young people engage in oral sex». Journal of Youth and Adolescence, 41 (5), 572-582. <https://doi.org/10.1007=s10964-012-9745-z>

WARD, L. Monique (2002). «Does television exposure affect emerging adults' attitudes and assumptions about sexual relationships?: Correlational and experimental confirmation». Journal of Youth and Adolescence, 31 (1), 1-15. <https://doi.org/10.1023/A:1014068031532>

- (2003). «Understanding the role of entertainment media in the sexual socialization of American youth: A review of empirical research». Developmental Review, 23 (3), 347-388. <https://doi.org/10.1016/s0273-2297(03)00013-3>

Weinberg, Martin S.; Williams, Colin J.; Kleiner, Sibyl e Irizarry, Yasmiyn (2010). «Pornography, normalization, and empowerment». Archives of Sexual Behavior, 39 (6), 1389-1401. <https://doi.org/10.1007=s10508-009-9592-5>

Wittig, Monique (1992a). «El pensamiento heterosexual». En: WitTig, Monique. El pensamiento heterosexual y otros ensayos. Barcelona: Egales, 2010.

- (1992b). «No se nace mujer». En: WitTig, Monique. El pensamiento heterosexual y otros ensayos. Barcelona: Egales, 2010.

Wright, Paul J.; Sun, Chyng; Steffen, Nicola J. y Tokunaga, Robert S. (2015). "Pornography, alcohol, and male sexual dominance». Communication Monographs, 82 (2), 252-270. <https://doi.org/10.1080/03637751.2014.981558>

Wright, Paul J.; Tokunaga, Robert S. y Kraus, Ashley (2015). "A meta-analysis of pornography consumption and actual acts of sexual aggression in general population studies». Journal of Communication, 66 (1), 183-205. <https://doi.org/10.1111/jcom.12201>

YaO, Mike Z.; Mahood, Chad y Linz, Daniel (2010). «Sexual priming, gender stereotyping, and likelihookd to sexually harass: examining the cognitive effects of playing a sexually-explicit video game». Sex Roles, 62, 77-88.

<https://doi.org/10.1007/s11199-009-9695-4> 